\title{
ON A NOTE OF GALBRAITH AND GREEN
}

\author{
EDMUND PINNEY
}

In a recent note $[1]^{1}$ Galbraith and Green evaluate the integral

$$
I_{n}=\frac{1}{\pi} \int_{0}^{x}\left[\frac{1+r^{2}}{1-r^{2}}-\frac{2 r}{1-r^{2}} \cos \theta\right]^{-n-1} d \theta .
$$

This may be identified with Laplace's second integral for the Legendre function. Thus if $\arg \left[\left(1+r^{2}\right) /\left(1-r^{2}\right)\right]<\pi / 2$, by $[2, \$ 15.23]$,

$$
I_{n}=P_{n}\left(\left[1+r^{2}\right] /\left[1-r^{2}\right]\right) \text {. }
$$

$\mathrm{By}^{2}[2, \S \S 14.51,15.22]$ this may be written

$$
\begin{aligned}
I_{n}= & {\left[\Gamma(-2 n-1) / \Gamma^{2}(-n)\right]\left(1 / r^{2}-1\right)^{n+1} F\left(n+1, n+1 ; 2 n+2 ; 1-1 / r^{2}\right) } \\
& +\left[\Gamma(2 n+1) / \Gamma^{2}(n+1)\right]\left(1 / r^{2}-1\right)^{-n} F\left(-n,-n ;-2 n ; 1-1 / r^{2}\right) .
\end{aligned}
$$

From this it is readily seen that

$$
\lim _{r \rightarrow 1^{-}}(1-r)^{n} I_{n}=2^{-n} \Gamma(2 n+1) / \Gamma^{2}(n+1) \quad \text { when } R(n)>-1 / 2 \text {, }
$$

(3) $\lim _{r \rightarrow 1^{-}}(1-r)^{-n-1} I_{n}=2^{n+1} \Gamma(-2 n-1) / \Gamma^{2}(-n) \quad$ when $R(n)<-1 / 2$.

The slight difference between (2) and Theorem 2 of Galbraith and Green's paper is due to an error in the latter. (3) does not appear in that paper.

\section{BIBLIOGRAPHY}

1. A. S. Galbraith and J. W. Green, $A$ note on the mean value of the Poisson kernel, Bull. Amer. Math. Soc. vol. 53 (1947) pp. 314-320.

2. Whittaker and Watson, Modern analysis, Cambridge University Press, 1935.

University OF California

Received by the editors May 12, 1947, and, in revised form, July 26, 1947.

1 Numbers in brackets refer to the bibliography at the end of the paper.

2 An error in $\$ 14.51$ of the reference may be corrected by changing the signs of the arguments of the gamma functions of binomial argument in the formula at the top of p. 289. 